\title{
Zukunftsperspektiven der Rechtsvergleichung
}

\author{
Hrsg. v. Reinhard Zimmermann
}

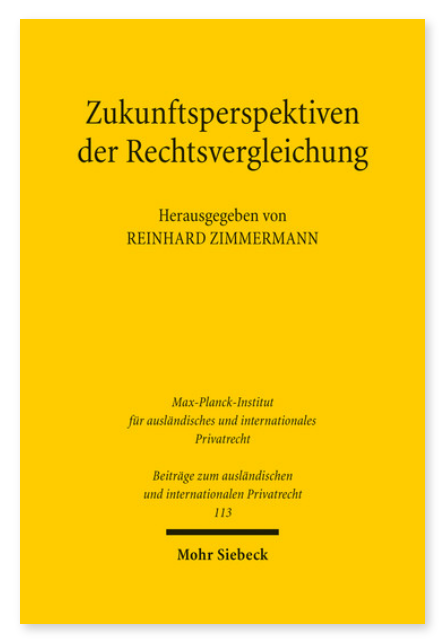

2016. XX, 267 Seiten. BtrIPR 113

ISBN 978-3-16-154950-2

DOI 10.1628/978-3-16-154950-2

eBook PDF
Dieser Band enthält die Beiträge zu einem Symposium aus Anlass des 80. Geburtstages von Hein Kötz. Sie stehen unter dem Obertitel »Zukunftsperspektiven der Rechtsvergleichung « und zeichnen sich durch einen weitgespannten Bogen an Themen und Methoden aus. Das ist ganz im Sinne eines Mannes, für den die Welt zu schwierig ist, als dass sie sich von einem Punkt aus kurieren ließe. Es geht um Kollisionsrecht, Sachenrecht, Unternehmensrecht und Deliktsrecht, um postsäkulare Rechtsvergleichung, Rechtssystemvergleichung und um den Wettbewerb der Rechtsordnungen; der rechtsdogmatische Zugriff wird verbunden mit nicht-dogmatischen Erkenntnissen; und immer wieder steht die Frage der Vergleichbarkeit im Mittelpunkt des Interesses: Was lässt sich wie womit sinnvollerweise vergleichen? Hein Kötz selbst plädiert in seinem Schlusswort dafür, sich mit der größten Gelassenheit allen Betrachtungsweisen zu öffnen, ohne jedoch der Illusion zu verfallen, endgültig und ein für alle Mal »richtige« Lösungen zu entwickeln.

Inhaltsübersicht

Reinhard Zimmermann: Keine Festschrift - Christiane Wendehorst: Rechtssystemvergleichung - Ralf Michaels: Religiöse Rechte und postsäkulare Rechtsvergleichung - Giesela Rühl: Rechtsvergleichung und europäisches Kollisionsrecht. Die vergessene Dimension - Eva-Maria Kieninger: Sachenrechtliche Prinzipien und Grundbegriffe als Gegenstände der Rechtsvergleichung - Gralf-Peter Calliess: Die Rolle der Rechtsvergleichung im Kontext des Wettbewerbs der Rechtsordnungen - Marc-Philippe Weller: Zukunftsperspektiven der Rechtsvergleichung im IPR und Unternehmensrecht - Jan von Hein: Marktregulierung durch Deliktsrecht. Zukunftsperspektiven der Rechtsvergleichung - Hein Kötz: Schlusswort

Reinhard Zimmermann ist Direktor am Max-Planck-Institut für ausländisches und internationales Privatrecht und Professor an der Bucerius Law School, Hamburg. https://orcid.org/0000-0003-0348-7929

Jetzt bestellen:

https://mohrsiebeck.com/buch/zukunftsperspektiven-der-rechtsvergleichung-9783161549502?no_cache=1 order@mohrsiebeck.com

Telefon: +49 (0)7071-923-17

Telefax: +49 (0)7071-51104 